\title{
Viabilidade econômica da produção de eucalipto no polo moveleiro de Marco - Ceará
}

Economic viability of eucalyptus production in the industrial furniture district of Marco - Ceará

\section{Fuad Pereira Nogueira Filho1*; Miklos Maximiliano Bajay²; João Alencar de Sousa³; José Dionis Matos Araújo ${ }^{4}$; Diva Correia ${ }^{5}$}

\footnotetext{
${ }^{1}$ Especialista em agronegócios - Rua Doutora Wanda Sidou, 7 - Cajazeiras - 60864-455 - Fortaleza, CE - Brasil <fuadnogueira@gmail.com>

${ }^{2}$ ESALQ/USP - Doutor em Genética e Melhoramento de Plantas - Av. Pádua Dias, 11 - 13418-900 - Piracicaba, SP - Brasil

${ }^{3}$ Embrapa Agroindústria Tropical - Doutor em Agronomia/Fitotecnia - Rua Sara Mesquita, 2270 - Pici - 60511-110 - Fortaleza, CE - Brasil

${ }^{4}$ Universidade Federal do Ceará - Mestre em Agronomia/Fitotecnia - Campus do Pici, bloco 805 - Pici - 60020-181 - Fortaleza, CE - Brasi

${ }^{5}$ Embrapa Agroindústria Tropical - Doutora em Recursos Florestais - Rua Sara Mesquita, 2270 - Pici - 60511-110 - Fortaleza, CE - Brasil
}

\section{Resumo}

A viabilidade econômica de projetos florestais é fortemente afetada pelo horizonte de tempo, os custos de produção, o preço da madeira, a produtividade do local e a taxa de desconto. Este trabalho analisou a viabilidade econômica da produção de madeira de eucalipto para o polo moveleiro de Marco-Ceará, em dois cenários: sem e com financiamento. Para a análise do projeto, utilizou-se o clone AEC 1528, considerando-se uma produtividade de 146,6, 376,4 e 316,1 $\mathrm{m}^{3} \mathrm{ha}^{-1}$ aos 7, 14 e 21 anos, respectivamente, simulado pelo software SISEucalipto. A madeira, cortada e empilhada na propriedade, foi destinada às indústrias de móveis e de cerâmica da região, conforme o sortimento de madeira por classe de diâmetro. A partir do fluxo de caixa, que abrangeu as atividades do plantio à colheita, foram obtidos indicadores de rentabilidade e de risco. Realizou-se, também, uma análise de sensibilidade, em que se avaliou o comportamento do valor presente líquido em função da variação do investimento inicial, da taxa de juros, do custo da colheita e dos preços da madeira. Os indicadores econômicos no cenário sem financiamento indicaram que o projeto deve ser aceito, possuindo uma boa rentabilidade. Ao incorporar o financiamento no projeto, utilizando a linha de crédito do programa ABC Florestas, constatou-se um aumento de seus indicadores quando comparado com o cenário sem financiamento. A produção de eucalipto no polo moveleiro de Marco-CE, apresentou-se viável economicamente nos dois cenários avaliados. A análise de sensibilidade demonstrou que o projeto possui um baixo risco, apesar do longo horizonte de tempo.

Palavras-chave: economia florestal, mensuração florestal, projetos florestais

\begin{abstract}
The economic viability of forestry projects is strongly affected by the time horizon, production costs, timber prices, site productivity, and the discount rate. This paper analyzed the economic viability of eucalyptus production in the industrial furniture of Marco-CE in two scenarios: with funding and without funding. For the project analysis, the AEC 1528 clone was used, considering a productivity of $146.6,376.4$ and $316.1 \mathrm{~m}^{3}$ $\mathrm{ha}^{-1}$ in 7,14 and 21 years, respectively, simulated by the software SISEucalipto. The cut and amassed lumber was destined to furniture and ceramic industries in the region, according to the variety of lumber for each class of industrial use. Profitability and risk indicators were obtained from the cash flow, which comprehended the activities from planting to harvesting. A sensitivity analysis was also carried out, which evaluated the behavior of the net present value according to the variation of the initial investment, the tax rate, harvesting costs and lumber prices. The economic indicators in the scenario without funding showed that the project should be accepted, with good profitability. Incorporating the project's funding, using the $\mathrm{ABC}$ Florestas credit line, evidenced an increase in the indicators when compared to the scenario without funding. The eucalyptus production in the industrial furniture district of Marco-CE was considered economically viable in both scenarios. The sensitivity analysis showed that the project has low risk, despite its long term.
\end{abstract}

Keywords: forest economy, forest mensuration, forestry projects

\section{Introdução}

Originárias da Oceania, as espécies do gênero Eucalyptus têm sido amplamente utilizadas em plantios florestais, devido à multiplicidade de usos e à melhoria do material genético e das técnicas silviculturais, proporcionando um aumento significativo de produtividade. Isso contribuiu para a projeção mundial do Brasil no setor florestal (Paiva et al., 2013).

No Brasil, a produção de eucalipto em escala comercial se iniciou em meados do século XX, com a finalidade de produzir lenha e dormentes para linhas férreas no estado de São Paulo. Contudo, apenas a partir da década de 70 houve um aumento significativo em área 
e produção, haja vista os programas de incentivos fiscais e os investimentos em pesquisa nos setores público e privado (Mora e Garcia, 2000).

O setor brasileiro de árvores plantadas cresceu historicamente a uma taxa de 3,8\% a.a. Em 2015, apesar dos cenários macroeconômicos desfavoráveis, o seu Produto Interno Bruto [PIB] setorial alcançou R \$ 69,1 bilhões, um aumento de 3\% em relação ao ano de 2014. Bastante significativo quando comparado com o desempenho da agropecuária $(+1,8 \%)$, indústria $(-6,2 \%)$ e do setor de serviços $(-2,7 \%)$. As exportações de seus produtos atingiram US\$ 9 bilhões, apresentando um desempenho positivo no saldo da balança comercial do setor (US\$ 7,7 bilhões), o que comprova a importância do setor de árvores plantadas para a economia nacional (IBÁ, 2016).

A competitividade da indústria brasileira de base florestal é decorrente da alta produtividade das árvores plantadas no País, que atingiu em média $36 \mathrm{~m}^{3} \mathrm{ha}^{-1}$ ano $^{-1}$ nos plantios de eucalipto no ano de 2015. A área de florestas plantadas no Brasil totalizou 7,8 milhões de hectares nesse mesmo período, dos quais os plantios de eucalipto representam $72 \%$ com 5,6 milhões de hectares. Ressalta-se que, da área plantada total, 34\% pertencem a empresas do segmento de celulose e papel; $29 \%$ referemse a proprietários independentes e fomentados, que comercializam a madeira in natura; $14 \%$ ao segmento de siderurgia a carvão vegetal; $6 \%$ pertencem a empresas do segmento de painéis de madeira e pisos laminados; e 4\% ao segmento de produtos sólidos de madeira (IBÁ, 2016).

A produção brasileira de madeira serrada, utilizada principalmente na construção civil e na produção de móveis, atingiu 8,8 milhões de $\mathrm{m}^{3}$ em 2015. Enquanto que a produção total de painéis compensados atingiu 2,6 milhões de $\mathrm{m}^{3}$. Nesse mesmo período, o consumo brasileiro de madeira in natura proveniente de plantios de eucalipto para uso industrial foi de 151,2 milhões de $\mathrm{m}^{3}$, dos quais 6,63 milhões de $\mathrm{m}^{3}(4,4 \%)$ e 1,65 milhões de $\mathrm{m}^{3}(1 \%)$ foram destinados aos segmentos da indústria madeireira e madeira tratada, respectivamente (IBÁ, 2016).

Embora esses percentuais revelem que, relativamente, há um pequeno volume de madeira de eucalipto destinado à produção de produtos sólidos de madeira, quando comparado aos demais segmentos (ex. carvão vegetal, celulose e papel), há uma oportunidade de utilização desta madeira na indústria moveleira e construção civil do Brasil.

O estado do Ceará está se consolidando como o maior polo moveleiro da região nordeste, com atuação nos mercados interno e externo, com aproximadamente 827 estabelecimentos moveleiros, dentre os quais se destaca o Arranjo Produtivo Local [APL] no município de Marco. Esse polo possui 27 indústrias de móveis, especializadas na produção de móveis residenciais e corporativos a partir de madeira sólida, chapas de fibras e de compensados (Scipião, 2004) ${ }^{1}$.

As empresas do polo moveleiro de Marco consomem em torno de $1.000 \mathrm{~m}^{3}$ mês $^{-1}$ de madeira serrada oriunda das regiões norte, sul e sudeste do país, uma vez que não há empreendimentos florestais no Ceará que atenda a demanda da indústria local. Estudos realizados evidenciaram que problemas relacionados à oferta de matéria-prima de qualidade, ao embargo a produtos sem certificação ambiental e à ausência de pesquisa sobre novas matérias-primas se constituem em ameaças às empresas moveleiras de Marco (AMMA, 2008).

Tais demandas evidenciam a importância de estudos relativos à viabilidade econômica de projetos florestais, que são incipientes e escassos na região de Marco-CE. Conforme Lima Júnior et al. (1999), o horizonte de tempo, os custos de produção, o preço da madeira, a produtividade do local e a taxa de desconto são fatores que compõe um conjunto de informações que o economista deve dispor para avaliar economicamente um projeto de investimento florestal. Diante do exposto, objetivou-se neste trabalho analisar a viabilidade econômica da produção de eucalipto no polo moveleiro de Marco-CE, em dois cenários: sem e com financiamento.

\section{Material e Métodos}

\section{Caracterização bioclimática da região de estudo}

Os estudos foram realizados no município de Acaraú, Ceará, no perímetro irrigado do Baixo Acaraú, região limítrofe ao polo moveleiro de Marco, a uma altitude de $56 \mathrm{~m}$, nas coordenadas geográficas: S $3^{\circ} 06^{\prime}$ 02" e W 40 04' 05". O clima da região é do tipo Aw' (tropical chuvoso) conforme a classificação de Köppen, com estação chuvosa de janeiro a maio e estação seca de junho a dezembro. A precipitação média anual varia em torno de $900 \mathrm{~mm}$; temperatura média anual igual a $28,1^{\circ} \mathrm{C}$; umidade relativa do ar média anual de $70 \%$; evaporação média anual de $1.600 \mathrm{~mm}$; insolação de 2.650 $\mathrm{h}$ ano $^{-1}$ e velocidade média dos ventos de $3 \mathrm{~m} \mathrm{~s}^{-1}$ (DNOCS, 2002). A área de implantação da floresta de eucalipto utilizada na simulação de plantio foi de aproximadamente 50 ha, cujo solo foi classificado como Neossolo Quartzarênico.

\section{Caracterização do manejo florestal e da implantação da floresta}

A partir das condições edafoclimáticas da região e de um teste de espécies arbóreas para a indústria do polo moveleiro de Marco-CE, conduzido pela Empresa Brasileira de Pesquisa Agropecuária [EMBRAPA]

\footnotetext{
${ }^{1}$ Scipião, T.T. 2004. Política industrial para promoção de arranjos produtivos locais: um estudo de caso em Marco - Ceará. 115 p. Dissertação de Mestrado em Políticas Públicas. Universidade Estadual do Ceará, Fortaleza, CE, Brasil. Disponível em:

<http://www.ric.ufc.br/observatorio/dis_tatianateofilo.PDF>. Acesso em: 22 ago. 2016.
} 
Agroindústria Tropical e EMBRAPA Florestas, utilizouse no projeto o clone AEC 1528, híbrido de base genética Eucalyptus grandis $\mathrm{x}$ Eucalyptus urophylla, com alta tolerância ao déficit hídrico.

Quanto às atividades de implantação da floresta, realizou-se o controle químico de plantas invasoras para limpeza da área; o combate às formigas, realizado de forma manual, que ocorreu em três fases, combate inicial, repasse e ronda, utilizando formicida granulado (Sulfluramida); correção e o preparo reduzido do solo; e o plantio mecanizado das mudas, realizado no período chuvoso. Contudo, nos períodos de estiagem, foram realizadas sete irrigações, aplicando de um a três litros por muda, até o estabelecimento das mudas. Para o replantio, considerou-se um índice de falhas nas linhas de plantio de $5 \%$. A adubação ocorreu em duas etapas (plantio e cobertura); sendo parceladas em quatro momentos distintos (uma no plantio das mudas, 3, 12 e 24 meses pós-plantio) (Paiva et al., 2013).

O sistema de plantio utilizado foi o povoamento de alto rendimento, com espaçamento de três metros entre as linhas e três metros entre plantas (1.111 plantas ha $\left.{ }^{-1}\right)$, ciclo de 21 anos, sendo realizados dois desbastes seletivos por baixo. Implementou-se um programa de desbastes para obtenção de madeira com maiores diâmetros. Para tanto, o primeiro desbaste ocorreu aos sete anos após o plantio, retirando-se $40 \%$ das árvores por hectare. No desbaste subsequente, aos 14 anos, também foram desbastadas $40 \%$ das árvores inicialmente existentes, totalizando 888 árvores desbastadas aos 21 anos e remanescendo 223 árvores até o corte final. Realizou-se, também, a desrama no segundo e quarto ano após o plantio, objetivando a produção de madeira de qualidade, livre de nós e com um núcleo nodoso menor e mais uniforme possível ao longo do fuste das árvores (Paiva et al., 2013).

A produtividade no primeiro e segundo desbaste $\mathrm{e}$ no corte final foi obtida por meio do software SISEucaliptoao simular o crescimento e a produção anual do povoamento, como também o sortimento de madeira por classe de diâmetro, considerando o comprimento das toras e a utilização final da madeira (ex. serraria ou energia). Para tanto, foram utilizados dados de inventário, obtidos a partir do teste de espécies realizado pela EMBRAPA Agroindústria Tropical e EMBRAPA Florestas, como o índice de sítio (38 m); o número de árvores por hectare (1.111); a idade do povoamento em que foi realizado o inventário (ano 2), um índice de homogeneidade do plantio igual a oito e o diâmetro quadrático médio $(12,21 \mathrm{~cm})$. Com base nos canais de comercialização da região (fábricas do polo moveleiro e indústrias de cerâmica), considerou-se o seguinte catálogo de produtos ao utilizar o SISEucalipto $^{2}$ : toras com diâmetro mínimo de $18 \mathrm{~cm} \mathrm{e}$ comprimento de $3,7 \mathrm{~m}$ (Serraria). As toras que não atenderam a essas especificações foram classificadas em produto destinado à geração de energia.

Com relação às operações de colheita, utilizou-se o sistema semimecanizado, a partir do qual ocorreram o corte das árvores e as operações de desgalha, traçamento e baldeio, empilhando as toras com casca próximo à estrada principal do perímetro irrigado do Baixo Acaraú. As operações de carregamento e transporte não foram realizadas, visto que, para o preço recebido pelo produtor, considerou-se a madeira empilhada na propriedade.

\section{Custos e receitas}

Foram levantados os custos de produção e as receitas, distribuídos ao longo da vida útil do projeto (21 anos). Para dimensionamento do fluxo de caixa, consideraram-se todas as atividades desde a implantação da floresta ao corte final. Na modalidade de produtor independente, despesas com mudas, insumos e colheita foram considerados. Os custos de produção foram subdivididos em dois centros: implantação (investimento inicial) e manutenção.

Com o intuito de evitar gastos com equipamentos pouco utilizados ao longo do projeto, realizou-se a terceirização de máquinas e equipamentos, com custo médio de hora-máquina de $\mathrm{R} \$ 90,00$, formado pela utilização de trator e implemento. A capacidade operacional das máquinas e implementos agrícolas, isto é, a quantidade de hectares executadas por unidade de tempo (ha $\mathrm{h}^{-1}$ ) foi calculada conforme a metodologia estabelecida por Pacheco (2000). O consumo médio de óleo diesel $\left(18,75 \mathrm{~L} \mathrm{~h}^{-1}\right)$ foi obtido considerando uma fonte de potência máxima de $105 \mathrm{cv}(77,2 \mathrm{~kW})$ de um trator BM $1004 \times 4$. Os preços do litro dos combustíveis - óleo diesel e gasolina - praticados na região foram de $\mathrm{R} \$ 3,00$ e $\mathrm{R} \$ 3,90$, respectivamente.

As operações relativas à colheita também foram terceirizadas, em que o valor do metro cúbico formado pelo fornecimento de mão de obra, máquinas e equipamentos foi de $\mathrm{R} \$ 46,00$. Esse custo apresenta-se elevado devido às operações de traçamento e empilhamento, ao sistema de colheita utilizado (semimecanizado com uso de motosserra) e também ao fato de existirem poucas prestadoras de serviço que atuem na região, distanciada dos grandes centros de produção florestal.

Com relação à mão de obra necessária, contrataramse funcionários para serviços temporários de inventário e marcação, execução e supervisão das operações silviculturais. A contratação foi efetuada por meio de contrato com prazo determinado (contrato a termo) regulado pela legislação trabalhista, no qual se contabilizou para cada contratado um salário mínimo no valor de $R \$ 880,00$, somado aos encargos salariais no valor de $\mathrm{R} \$ 250,27$, que corresponde a $28,44 \%$ do salário

2 Sistema para manejo de florestas de eucalipto desenvolvido pela EMBRAPA, lançado em 2001. Disponível em:

<https://www.EMBRAPA.br/florestas/transferencia-de-tecnologia/softwares-florestais>. Acesso em: 25 ago. 2016 
mensal pago pelo empregador (BRASIL, 1973; Bacha, 2014). Além disso, computou-se também a verba especial safrista equivalente a $8,33 \%$ do salário mensal (R\$73,30) e os encargos não dependentes do salário, vale alimentação $(R \$ 200,00)$ e vale transporte $(R \$ 180,00)$, totalizando um custo mensal por funcionário de $\mathrm{R} \$$ 1.583,57. A quantidade de mão de obra utilizada nas atividades baseou-se nas operações realizadas e no rendimento médio por homem.

Contrataram-se também serviços de assistência técnica para acompanhamento durante a implantação e manutenção do povoamento, com sete visitas periódicas nas fases de implantação, desrama, desbaste e corte final, e cada visita orçada no valor de $\mathrm{R} \$ 7.500,00$. Além disso, computou-se também a tarifa anual por hectare de $\mathrm{R} \$$ 144,00 paga pelo usuário em função da vazão de água disponibilizada, energia elétrica e de outros serviços e infraestrutura oferecidos no perímetro irrigado do Baixo Acaraú.

\section{Custos de implantação}

A composição dos custos de implantação foi contabilizada a partir das atividades apresentadas na Tabela 1.

Tabela 1. Custos de implantação de eucalipto no polo moveleiro de Marco-CE

\begin{tabular}{|c|c|c|c|c|}
\hline \multirow[b]{2}{*}{ Descrição } & \multirow[b]{2}{*}{ Especificação } & \multirow[b]{2}{*}{ Valor unitário } & \multicolumn{2}{|c|}{ Ano 0} \\
\hline & & & Quantidade & Total \\
\hline & & --- R\$ --- & & ---R\$--- \\
\hline \multicolumn{5}{|l|}{ A - Custos de implantação } \\
\hline A.1. Aquisição de mudas & unidade & 0,50 & 58.327 & $29.163,50$ \\
\hline \multicolumn{5}{|l|}{ A.2. Limpeza da área } \\
\hline Máquina (pulverizador) & Hora-máquina & 90,00 & 15 & $1.350,00$ \\
\hline Herbicida (pós-emergente) & $\mathrm{L}^{1}$ & 16,00 & 200 & $3.200,00$ \\
\hline \multicolumn{5}{|l|}{ A.3 Combate às formigas } \\
\hline Inicial - Formicida & $\mathrm{kg}$ & 21,50 & 125 & $2.687,50$ \\
\hline Repasse - Formicida & $\mathrm{kg}$ & 21,50 & 50 & $1.075,00$ \\
\hline \multicolumn{5}{|l|}{ A.4 . Correção do solo } \\
\hline Calcário+Frete & $\mathrm{t}$ & 115,00 & 75 & $8.625,00$ \\
\hline Máquina distribuidora & Hora-máquina & 90,00 & 7 & 630,00 \\
\hline \multicolumn{5}{|l|}{ A.5. Preparo reduzido do solo } \\
\hline Análise de solo & Amostra & 40,00 & 5 & 200,00 \\
\hline Subsolagem+Adubação & Hora-máquina & 90,00 & 89 & $8.010,00$ \\
\hline Fertilizante (06-30-06) & $\mathrm{kg}$ & 1,46 & 5.55 & $8.103,00$ \\
\hline Micronutrientes (formulação*) & $\mathrm{kg}$ & 2,00 & 850 & $1.700,00$ \\
\hline \multicolumn{5}{|l|}{ A.6. Plantio } \\
\hline Máquina (plantadora) & Hora-máquina & 150,00 & 41 & $6.150,00$ \\
\hline Máquina (pulverizador) & Hora-máquina & 90,00 & 15 & $1.350,00$ \\
\hline Herbicida (pré-emergente) & $\mathrm{kg}$ & 690,75 & 5 & $3.453,75$ \\
\hline A.7. Irrigação (carreta-pipa) & Hora-máquina & 90,00 & 50 & $4.500,00$ \\
\hline \multicolumn{5}{|l|}{ A.8. Tratos Culturais } \\
\hline Fertilizante (20-00-20) & $\mathrm{kg}$ & 1,27 & 11.1 & $14.097,00$ \\
\hline Máquina (adubadora) & Hora-máquina & 90,00 & 27 & $2.430,00$ \\
\hline Máquina (pulverizador) & Hora-máquina & 90,00 & 57 & $5.130,00$ \\
\hline Herbicida (pós-emergente) & $\mathrm{L}^{\mathrm{I}}$ & 16,00 & 200 & $3.200,00$ \\
\hline A.9. Mão-de-obra & mês/funcionário & $1.583,57$ & 18 & $28.504,26$ \\
\hline A.10. Combustível (óleo diesel) & $\mathrm{L}$ & 3,00 & 5.643 & $16.931,25$ \\
\hline A.11. Assistência técnica & serviço & $7.500,00$ & 1 & $7.500,00$ \\
\hline A.12. Outras Despesas & & & & $8.221,40$ \\
\hline Total & & & & $166.211,66$ \\
\hline
\end{tabular}

As mudas do clone AEC 1528 totalizaram 58.327 em 50 hectares, no qual se incluiu 5\% para recomposição do povoamento por meio do replantio. $\mathrm{O}$ valor por muda foi de $\mathrm{R} \$ 0,50$, incluído o valor do frete.

Para execução e supervisão das operações referentes à implantação da floresta, contratou-se três funcionários por um período de seis meses.
Com relação ao controle de plantas invasoras, para limpeza da área, realizou-se o controle químico, aplicando em área total quatro litros de herbicida pósemergente (glyphosate) por hectare antes do plantio $(\mathrm{R} \$$ 16,00 L-1), dessecando-as. Logo após o plantio das mudas, aplicou-se herbicida pré-emergente (isoxaflutol) na linha de plantio, utilizando uma dose de $100 \mathrm{~g} \mathrm{ha}^{-1}(\mathrm{R} \$$ $\left.690,75 \mathrm{~kg}^{-1}\right)$. Com seis meses após o plantio, aplicou-se 
novamente o glyphosate, em jato dirigido nas entre linhas, evitando o contato com as mudas (Wilcken et al., 2008; MAPA, 2016).

No combate inicial às formigas, após a limpeza da área, utilizou-se $2,5 \mathrm{~kg}$ de isca granulada por hectare $(\mathrm{R} \$$ 21,50 $\left.\mathrm{kg}^{-1}\right)$, enquanto que no repasse, realizado dois meses após o combate inicial, aplicou-se $1 \mathrm{~kg} \mathrm{ha}^{-1}$ (Paiva et al., 2013).

Realizaram-se cinco análises de solo no valor de $\mathrm{R} \$$ 40,00 por amostra, considerando uma amostra para cada 10 hectares. Quanto à correção do solo, foram aplicados $1.500 \mathrm{~kg}$ de calcário dolomítico por hectare $(\mathrm{R} \$ 115,00 \mathrm{t}$ 1) dois meses antes do plantio. Em seguida, procedeu-se ao preparo reduzido do solo, em que foi subsolada a linha de plantio a uma profundidade de $50 \mathrm{~cm}$.

A adubação no plantio foi realizada de forma mecanizada em conjunto com a operação de subsolagem, aplicando-se $100 \mathrm{~g}$ de NPK 06-30-06 no interior do sulco de plantio, totalizando $111 \mathrm{~kg} \mathrm{ha}^{-1}\left(\mathrm{R} \$ 1,46 \mathrm{~kg}^{-1}\right)$. Aplicou-se também $15 \mathrm{~g}$ do fertilizante composto por micronutrientes, resultando em $17 \mathrm{~kg} \mathrm{ha}^{-1}\left(\mathrm{R} \$ 2,00 \mathrm{~kg}^{-1}\right)$. Quanto à adubação de cobertura, aplicaram-se $200 \mathrm{~g}$ de NPK (20-00-20) aos três meses após o plantio, totalizando $222 \mathrm{~kg} \mathrm{ha}^{-1}\left(\mathrm{R} \$ 1,27 \mathrm{~kg}^{-1}\right.$ ) (Paiva et al., 2013).

Empregou-se o plantio mecanizado das mudas e, posteriormente, efetuou-se a irrigação até o estabelecimento das mudas.

\section{Custos de manutenção}

Os custos de manutenção abrangeram o controle químico de plantas invasoras, a adubação de cobertura $(\mathrm{KCl})$, o combate às formigas (ronda), o controle de doenças, as desramas, os desbastes, a colheita (corte final), a mão de obra, o combustível (óleo diesel e gasolina), os tributos, a tarifa, a assistência técnica e o custo de oportunidade da terra.

No controle de plantas invasoras, aplicaram-se quatro litros de glyphosate por hectare aos 12 e 18 meses após o plantio (Wilcken et al., 2008).

$\mathrm{Na}$ adubação de cobertura, aplicaram-se $200 \mathrm{~g}$ de $\mathrm{KCl}$ aos 12 e 24 meses após o plantio, totalizando $222 \mathrm{~kg}$ $\mathrm{ha}^{-1}\left(\mathrm{R} \$ 1,37 \mathrm{~kg}^{-1}\right)$ em cada um desses períodos (Paiva et al., 2013). O combate às formigas foi feito durante todo o ciclo do povoamento, aplicando-se em cada ano $2 \mathrm{~kg}$ de isca granulada por hectare. Aos 12 meses após o plantio, foram aplicados $0,4 \mathrm{~L} \mathrm{ha}^{-1}$ de fungicida sistêmico (azoxistrobina) (MAPA, 2016).

No que se refere à desrama, utilizaram-se os seguintes equipamentos e utensílios: escadas de alumínio, motopodadores (consumo de 0,7 L de gasolina) e equipamentos de proteção individual. Tais bens foram registrados como despesa operacional e não foram submetidos à depreciação fiscal por possuírem valor unitário inferior a $\mathrm{R} \$ 1.200,00$, conforme estabelece o art. 15 da Lei 12.973/2014 (BRASIL, 2014).

A primeira operação da desrama, realizada no segundo ano, abrangeu todas as árvores do povoamento (poda baixa de até $6 \mathrm{~m}$ da altura do solo), haja vista um maior rendimento operacional (em média 1 min árvore ${ }^{-1}$ operador $\left.^{-1}\right)$. Na segunda operação, realizada no quarto ano, foram desramadas apenas as árvores submetidas ao corte final (poda alta de até $9 \mathrm{~m}$ da altura do solo) com rendimento operacional médio de 2 min árvore ${ }^{-1}$ operador $^{-1}$ (Foelkel, 2010).

Para execução dessas operações, foram contratados no segundo ano quatro funcionários pelo prazo de um mês e, no quarto ano, dois funcionários pelo mesmo prazo. Nos demais anos do projeto foram contratados um funcionário pelo prazo de um mês para supervisão e execução de operações.

Aos 7 e 14 anos após a implantação, aplicou-se o desbaste seletivo por baixo, isto é, removeram-se as árvores das classes de copas mais baixas (árvores dominadas). No primeiro desbaste a produtividade foi de $146,6 \mathrm{~m}^{3} \mathrm{ha}^{-1}$ com o seguinte sortimento de madeira por classe diamétrica: $13,3 \mathrm{~m}^{3} \mathrm{ha}^{-1}$ para serraria e $133,3 \mathrm{~m}^{3}$ $\mathrm{ha}^{-1}$ para energia. No segundo desbaste a produtividade foi de $376,4 \mathrm{~m}^{3}$ ha-1 com a seguinte classe de sortimento: $234,1 \mathrm{~m}^{3} \mathrm{ha}^{-1}$ para serraria e $142,2 \mathrm{~m}^{3} \mathrm{ha}^{-1}$ para energia. As árvores foram cortadas, desgalhadas, traçadas em toras de $3,70 \mathrm{~m}$ e posteriormente empilhadas. Os volumes gerados por classe de sortimento no primeiro e segundo desbastes estão apresentados na tabela 2 .

$\mathrm{Na}$ colheita (corte final), removeram-se 223 árvores por hectare remanescentes do povoamento, efetuandose também o corte, a desgalha, o traçamento em toras de $3,70 \mathrm{~m}$ e o empilhamento, resultando em uma produtividade de $316,1 \mathrm{~m}^{3} \mathrm{ha}^{-1}$, sendo este volume destinado à serraria $\left(251,4 \mathrm{~m}^{3} \mathrm{ha}^{-1}\right)$ e à energia $\left(64,6 \mathrm{~m}^{3}\right.$ $\mathrm{ha}^{-1}$ ) (Tabela 2). Quanto aos tributos, incidiram no projeto: a Contribuição ao Fundo de Assistência ao Trabalhador Rural [FUNRURAL], com alíquota de 2,3\% sobre o total das receitas obtidas no projeto; a Contribuição Sindical Rural, com alíquota de $0,1 \%$ sobre o valor da terra nua tributável de $\mathrm{R} \$ 4.000,00 \mathrm{ha}^{-1}$, adicionando-se uma parcela de $\mathrm{R} \$ 128,16$; e o Imposto sobre a Propriedade Territorial Rural [ITR] com alíquota de $0,07 \%$ sobre o valor da terra nua de $\mathrm{R} \$ 4.000,00 \mathrm{ha}^{-1}$, considerando a área total do imóvel (80 ha), o grau de utilização (maior que $80 \%$ ) e a área sujeita à tributação (50 ha). Incidiu também o imposto de renda de pessoa física pela escrituração do livro caixa, no qual se registrou todas as receitas e despesas (investimento e de custeio), apurando-se o lucro real, considerando as devidas compensações (prejuízos acumulados) (Bacha, 2014). 
Tabela 2. Sortimento da madeira do clone AEC 1528 (Eucalyptus grandis × Eucalyptus urophylla) por classe diamétrica das árvores provenientes do primeiro desbaste aos 7 anos, aos 14 anos e aos 21 anos

\begin{tabular}{|c|c|c|c|c|c|}
\hline \multicolumn{4}{|c|}{ Variáveis* } & \multicolumn{2}{|c|}{ Uso Industrial* } \\
\hline Classes (DAP**) & Povoamento & Altura Média & Volume Total & Serraria & Energia \\
\hline ------------- cm -------------- & ----- Árvore ha-1 ---- & ---------- m ----------- & $\begin{array}{ll}--------------------------- \\
\end{array}$ & ha ${ }^{-1}-----------$ & ------------ \\
\hline \multicolumn{6}{|c|}{ Desbaste aos 7 anos } \\
\hline $14-16$ & 2 & 29,2 & 0,4 & 0 & 0,4 \\
\hline $16-18$ & 58 & 30,8 & 16,5 & 0 & 16,6 \\
\hline $18-20$ & 237 & 31,7 & 83,7 & 0 & 83,7 \\
\hline $20-22$ & 93 & 32,4 & 38,7 & 9,9 & 28,8 \\
\hline $22-24$ & 14 & 31,7 & 6,9 & 3,2 & 3,7 \\
\hline $24-26$ & 1 & 32,3 & 0,4 & 0,3 & 0,1 \\
\hline Totais & & 32,1 & 146,6 & 13,3 & 133,3 \\
\hline \multicolumn{6}{|c|}{ Desbaste aos 14 anos } \\
\hline $24-26$ & 424 & 43,9 & 373,2 & 231,6 & 141,6 \\
\hline $26-28$ & 3 & 47,3 & 3,2 & 2,5 & 0,7 \\
\hline Totais & & 46,4 & 376,4 & 234,1 & 142,2 \\
\hline \multicolumn{6}{|c|}{ Desbaste aos 21 anos } \\
\hline $28-30$ & 206 & 54,4 & 289,4 & 228,8 & 60,5 \\
\hline $30-32$ & 17 & 55,5 & 26,7 & 22,6 & 4,1 \\
\hline Totais & & 53,9 & 316,1 & 251,4 & 64,6 \\
\hline
\end{tabular}

O custo de oportunidade da terra consistiu no valor do arrendamento dos lotes do Perímetro Irrigado do Baixo Acaraú ( $\left.\mathrm{R} \$ 36.000,00 \mathrm{ano}^{-1}\right)$.

\section{Receitas}

A partir das estimativas do volume de madeira e do preço unitário do produto, obtido junto às fábricas do polo moveleiro e indústrias de cerâmica do Ceará, foram estimadas as receitas durante o prazo de análise do projeto.

O preço da madeira cortada e empilhada na propriedade variou conforme a classe de utilização industrial (Tabela 3).

Tabela 3. Preço da madeira de eucalipto estimado por uso industrial, em vigor no quarto trimestre de 2016 no estado do Ceará

\begin{tabular}{|c|c|c|c|}
\hline Uso Industrial & Sortimento & Comprimento & Preço* \\
\hline & ---------- cm ----------- & --------------- $m$---------------- & ---- $\mathrm{R} \$ \mathrm{~m}^{-3}$----- \\
\hline Serraria & $\geq 18$ & 3,7 & 200,00 \\
\hline Energia & $<18$ & 3,7 & 55,00 \\
\hline
\end{tabular}

*preço médio praticado na região de estudo

\section{Fluxo de caixa}

O fluxo de caixa consiste em um método que captura e registra valores que alteram o saldo de caixa, isto é, uma sucessão de entradas e/ou saídas de valores monetários ao longo de um determinado período de tempo (Sá, 2014). Para o seu dimensionamento foram consideradas receitas e despesas constantes, cujas estimativas monetárias não incluem a correção futura dos preços devido à inflação.

Para a análise econômica do projeto, utilizou-se uma Taxa Mínima de Atratividade real [TMA] de 6,38\% a.a., calculada por meio da taxa de juros nominal do Sistema Especial de Liquidação e Custódia [SELIC] de 14,19\% a.a, descontada por uma taxa de inflação de 7,34\% medida pelo Índice Nacional de Preços ao Consumidor Amplo [IPCA] (BCB, 2016).

O projeto foi avaliado em dois cenários: sem financiamento e com financiamento. Para tanto, incorporou-se ao fluxo de caixa um financiamento utilizando a linha de crédito do programa ABC Florestas, com a finalidade de financiar $50 \%$ dos custos de implantação. A taxa de juros real do financiamento foi de 1,08\% a.a, obtida pela taxa de juros nominal de 8,5\% a.a, descontada pela taxa de inflação de $7,34 \%$ medida pelo IPCA. Os prazos de reembolso e de carência foram de 15 e 6 anos, respectivamente (SFB, 2016).

\section{Indicadores econômicos Valor Presente Líquido [VPL]}

A medição de valor do projeto é realizada pelo VPL do fluxo de caixa, considerando um determinado custo de oportunidade. Nesse sentido, para criar valor, o preço a pagar pelo projeto deverá ser menor do que o valor de seus retornos, cuja determinação depende das estimativas futuras das receitas, dos custos e do custo e oportunidade correspondente ao risco (Lapponi, 2007).

O custo inicial da maioria dos projetos ocorre na data inicial do prazo de análise, assim, as empresas tomam 
decisões entre alternativas possíveis avaliadas na data inicial. Nesses casos, o VPL é o procedimento de avaliação indicado, uma vez que mede o lucro econômico ou o valor criado pelo projeto na data da tomada de decisão de investimento. Portanto, se o VPL for maior do que zero, o projeto deverá ser aceito, pois criará valor para a empresa; se o VPL for menor do que zero, o projeto não deve ser aceito, pois, caso seja executado, destruirá o valor da empresa. Se o VPL for igual a zero, o capital será recuperado e remunerado com a taxa requerida, porém não criará nem destruirá valor (Lapponi, 2007). O cálculo do VPL está apresentado na eq. (1).

$$
\mathrm{VPL}=\sum_{\mathrm{t}=1}^{\mathrm{n}} \frac{\mathrm{FC}_{\mathrm{t}}}{(1+\mathrm{i})^{\mathrm{t}}}-\mathrm{I}_{0}
$$

onde, $\mathrm{FC}_{\mathrm{t}}$ : fluxo de caixa no período $\mathrm{t} ; \mathrm{I}_{0}$ : investimento inicial; i: taxa de juros; t: período de tempo analisado; e, n: número de períodos.

\section{Valor Presente Líquido Anualizado [VPLa]}

A interpretação do valor monetário do VPL apresenta dificuldades para comparação, principalmente em relação a projetos com horizontes de planejamento longos. Uma alternativa é considerar um VPL médio (equivalente) para cada um dos períodos do projeto. Enquanto o VPL concentra todos os valores do fluxo de caixa na data zero, no VPLa o fluxo de caixa representativo do projeto de investimento é transformado em uma série uniforme (Souza e Clemente, 2008). O VPLa foi obtido a partir da eq. (2).

$$
\mathrm{VPLa}=\mathrm{VPL} \frac{\mathrm{i}(1+\mathrm{i})^{\mathrm{n}}}{(1+\mathrm{i})^{\mathrm{n}}-1}
$$

onde, VPLa: valor presente líquido anualizado; i: taxa de juros; e, n: número de períodos.

\section{Taxa Interna de Retorno [TIR]}

A TIR é a taxa efetiva do fluxo de caixa do projeto ou a taxa esperada pelo projeto. É também a taxa que zera o VPL do projeto. Além disso, a TIR é um ponto de reversão da decisão de aceitação do projeto, pois se a taxa requerida (ou taxa mínima de atratividade) for menor do que a TIR o projeto deve ser aceito; caso contrário, se a taxa requerida for maior do que a TIR o projeto deve ser rejeitado, porque destruirá valor da empresa (Lapponi, 2007). O cálculo da TIR está descrito na eq. (3)

$$
0=\sum_{\mathrm{t}=1}^{\mathrm{n}} \frac{\mathrm{FC}_{\mathrm{t}}}{(1+\mathrm{i})^{\mathrm{t}}}-\mathrm{I}_{0}
$$

onde, $\mathrm{FC}_{\mathrm{t}}$ : fluxo de caixa no período $\mathrm{t}$; $\mathrm{I}_{0}$ : investimento inicial; i: taxa de juros; t: período de tempo analisado; e, n: número de períodos.

\section{Índice de Lucratividade [IL]}

O IL é a divisão da soma a valor presente dos retornos do projeto, considerando determinada taxa requerida, pelo seu custo inicial. Portanto, o IL mensura o valor do projeto por unidade de investimento inicial na data zero do fluxo de caixa, ou seja, a cada unidade de investimento inicial $\$ 1$ na data inicial o projeto gerará \$IL da soma dos valores presentes dos retornos, também mensurados na mesma data inicial (Lapponi, 2007). O IL foi obtido a partir da eq. (4).

$$
\mathrm{IL}=\frac{\sum_{\mathrm{t}=1}^{\mathrm{n}} \frac{\mathrm{FC}}{(1+\mathrm{t})^{\mathrm{t}}}}{\mathrm{I}_{0}}
$$

onde, $\mathrm{FC}_{\mathrm{t}}$ : fluxo de caixa no período $\mathrm{t}$; $\mathrm{I}_{0}$ : investimento inicial; i: taxa de juros; t: período de tempo analisado; e, n: número de períodos.

O IL também pode ser apresentado em percentual $(\%)$, conforme a eq. (5), e se refere à taxa de retorno adicional do investimento durante a vida útil do projeto

$$
\mathrm{IL}_{\%}=(\mathrm{IL}-1) * 100
$$

\section{Retorno Adicional sobre o Investimento [ROIA]}

De acordo com Souza e Clemente (2008), o ROIA é a melhor estimativa de rentabilidade para um projeto de investimento, representando em termos percentuais a riqueza gerada pelo projeto, ou seja, é o excedente em percentual de retorno oferecido pelo projeto acima da taxa requerida (taxa mínima de atratividade). O ROIA deriva da taxa equivalente ao Índice de Lucratividade para cada período do projeto. $\mathrm{Na}$ eq. (6) está descrito o cálculo do ROIA.

$$
\mathrm{ROIA}=\left(\left(1+\mathrm{IL}_{\%}\right)^{\frac{1}{\mathrm{n}}-1}\right) * 100
$$

onde, ROIA: retorno adicional sobre o investimento; IL $\%$ : índice de lucratividade em percentual no período; e, n: número de períodos.

\section{Retorno sobre Investimento [ROI]}

O retorno sobre o capital investido é obtido quando se aplicam os recursos liberados pelo projeto à taxa mínima de atratividade (Souza e Clemente, 2008). O ROI pode ser calculado pela seguinte eq. (7).

$$
\mathrm{ROI}=((1+\mathrm{TMA}) *(1+\mathrm{ROIA})-1) * 100
$$

onde, ROI: retorno sobre o investimento; TMA: taxa mínima de atratividade; e, ROIA: retorno adicional sobre o investimento.

\section{Payback simples e descontado}

O período de recuperação do investimento ou payback é o número de períodos necessários para que o 
fluxo de benefícios supere o capital investido (Souza e Clemente, 2008).

O payback descontado é o tempo necessário para recuperar o custo inicial remunerado, considerando o valor do dinheiro no tempo (Lapponi, 2007). O cálculo do payback descontado foi obtido por meio da eq. (8).

$$
\mathrm{I}_{0}=\sum_{\mathrm{t}=1}^{\mathrm{n}} \frac{\mathrm{FC}_{\mathrm{t}}}{(1+\mathrm{i})^{\mathrm{t}}}
$$

onde, $\mathrm{FC}_{\mathrm{t}}$ : fluxo de caixa no período $\mathrm{t}$; $\mathrm{I}_{0}$ : investimento inicial; i: taxa de juros; t: tempo para recuperar o investimento inicial; e, n: número de períodos.

\section{Análise de sensibilidade}

Cada estimativa (preço unitário, custo unitário, custo inicial, entre outros) utilizada no dimensionamento do fluxo de caixa do projeto é o valor mais provável ou esperado de seu intervalo de valores possíveis. Contudo, os futuros valores realizados dessas estimativas serão diferentes, pois haverá desvios dos respectivos valores esperados. Do mesmo modo, os valores realizados do fluxo de caixa e do VPL também serão diferentes das suas respectivas estimativas esperadas. A ocorrência desses desvios é o que caracteriza a incerteza do projeto, e o grau desses desvios é o que determina o risco do projeto (Lapponi, 2007).

Quanto aos riscos do projeto em estudo, destacaramse o risco de produção, já considerado na simulação da produtividade da floresta; e o risco de preço da madeira destinada aos mercados de energia e serraria. Para análise do risco do projeto, realizou-se uma análise de sensibilidade, em que se avaliou o comportamento do VPL em função da variação do investimento inicial, da taxa de juros, do custo da colheita e dos preços da madeira destinada à serraria e à energia, alternando cada estimativa no intervalo de $-30 \%$ a $+30 \%$, escalonadas de 5 em $5 \%$.

\section{Resultados e Discussão}

\section{Custos de produção do eucalipto}

$O$ valor presente líquido anualizado do custo total de produção foi de $\mathrm{R} \$ 144.026,62$ ou $\mathrm{R} \$ 2.880,53$ que corresponde ao custo médio por hectare da produção de eucalipto na região em estudo.

Esse valor foi próximo ao obtido pela FAMATO (2013) ao avaliar o custo total de produção $(\mathrm{R} \$ 2.267,38$ $\mathrm{ha}^{-1} \mathrm{ano}^{-1}$ ) do eucalipto com ciclo de 12 anos destinado à serraria no estado do Mato Grosso, considerando uma taxa de desconto de $5 \%$ ao calcular o valor presente líquido dos desembolsos. Essa diferença se deve ao fato do município de Marco-CE estar distante dos grandes centros de produção de madeira, elevando os custos na região.

Além disso, nos últimos anos, a produção de madeira ficou mais cara no País conforme evidencia o relatório anual da Indústria Brasileira de Árvores [IBÁ]. Em 2015, a inflação do setor de árvores plantadas, medida pelo Índice Nacional de Custos da Atividade Florestal [INCAF-Pöyry], foi de 12,8\%, enquanto que a inflação nacional medida pelo IPCA ficou em 10,7\% (IBÁ, 2016).

No que se refere aos custos de implantação, observou-se que a aquisição de mudas foi o custo mais significativo (17,5\%); seguido da mão de obra $(17,1 \%)$; dos tratos culturais $(14,9 \%)$, que envolveram as operações de adubação de cobertura e aplicação de herbicida pós-emergente; das operações do preparo do solo (10,8\%); do combustível (10,1\%); e das operações de plantio $(6,6 \%)$ e correção do solo $(5,6 \%)$. As operações de limpeza da área, irrigação e combate às formigas representaram 2,7\%, 2,7\% e 2,3\%, respectivamente. Enquanto que os gastos com assistência técnica e outras despesas foram de $\mathrm{R} \$ 7.500$ (4,5\%) e R $\$ 8.221,40$ (4,5\%), respectivamente.

Os custos de manutenção foram representados em boa parte pelos custos de desbastes e corte final (57,5\% do custo total), referente às operações de corte, traçamento e baldeio. Tais custos foram contabilizados devido à exigência das fábricas pertencentes ao polo moveleiro com relação à forma de aquisição da madeira (madeira cortada e empilhada na propriedade). Em consequência, houve um ganho no preço pago ao produtor.

Ainda com relação aos custos de manutenção, o custo de oportunidade da terra correspondeu a $23,7 \%$ do total dos custos de manutenção. Os tributos, exceto o imposto de renda, e a tarifa do perímetro irrigado, também tiveram participação significativa nos custos de manutenção, correspondendo a 9,3\%.

Quanto ao Imposto de Renda Pessoa Física [IRPF], contabilizou-se $\mathrm{R} \$ 266.132,88$ aos 14 anos e $\mathrm{R} \$$ 419.502,66 aos 21 anos do projeto sem financiamento, apurados quando as receitas superaram os custos, considerando as devidas compensações legais. Com base no VPL do projeto, embora os valores arrecadados neste projeto sejam elevados, o lucro real para o produtor rural (pessoa física) é mais vantajoso do que o lucro presumido como regime de tributação a ser adotado.

\section{Viabilidade econômica do projeto sem e com financiamento}

O fluxo de caixa líquido do projeto de investimento florestal, utilizando recursos próprios, é formado por desembolsos (custos de implantação e manutenção) e recebimentos, gerados pela comercialização da madeira proveniente dos desbastes (aos 7 e 14 anos) e do corte final (aos 21 anos) (Figura 1). Trata-se de um fluxo de caixa não convencional com cinco mudanças de sinais.

A partir das estimativas durante o prazo de análise do projeto, calcularam-se os indicadores econômicos descritos na Tabela 4. 


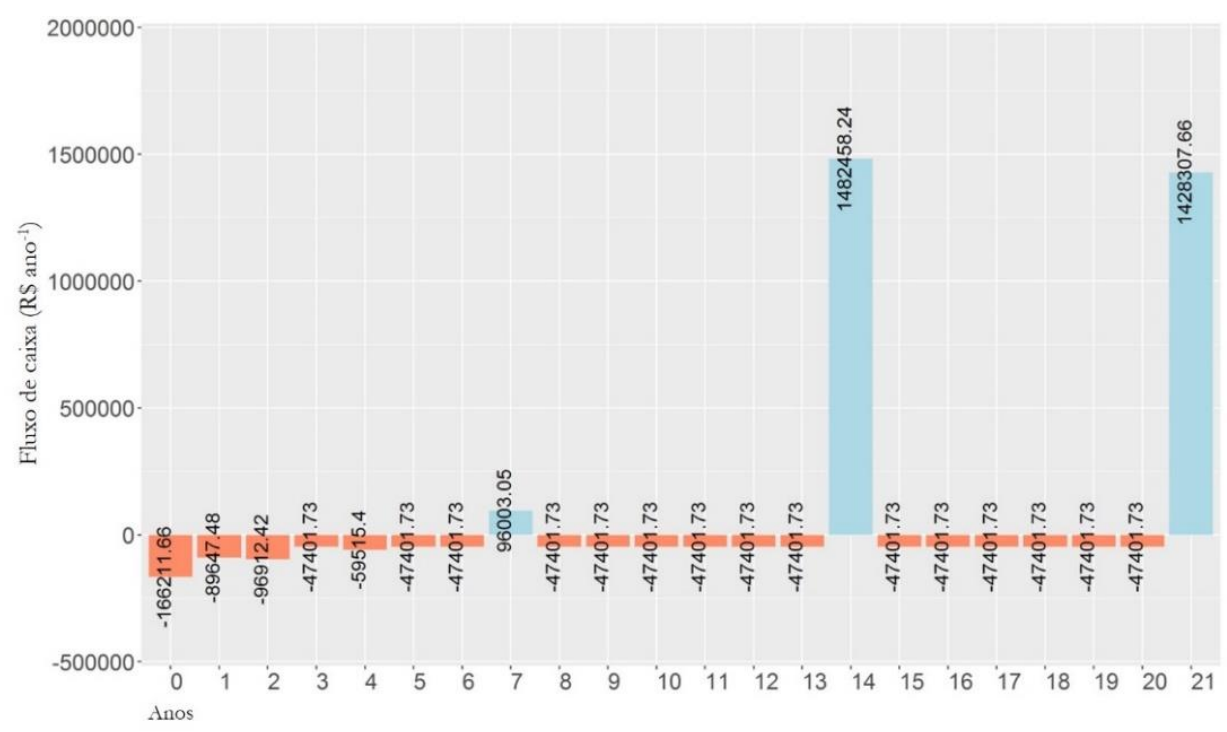

Figura 1. Fluxo de caixa do projeto sem financiamento em um horizonte de planejamento de 21 anos

Tabela 4. Indicadores econômicos do projeto de investimento florestal, utilizando recursos próprios, em Marco-CE

\begin{tabular}{lrr}
\hline Indicadores econômicos & Unidade & Valores esperados \\
\hline Valor Presente Líquido [VPL] (6,38\%) & $\mathrm{R} \$$ & $339.890,84$ \\
Valor Presente Líquido Anualizado [VPLa] & $\mathrm{R} \$$ & $29.822,38$ \\
Taxa Interna de Retorno [TIR] & $\%$ & 10,19 \\
Índice de Lucratividade [IL] & $\%$ & 3,04 \\
Índice de Lucratividade em Percentual [IL\%] & $\%$ & 204 \\
Retorno Adicional sobre o Investimento [ROIA] & $\%$ & 5,45 \\
Retorno sobre o Investimento [ROI] & & 12,17 \\
Payback descontado & & Não se aplica \\
Payback simples & 14 \\
\hline
\end{tabular}

Considerando a taxa requerida de 6,38\% a.a, o VPL positivo igual a $\mathrm{R} \$ 339.890,84$ evidencia que o projeto deve ser aceito, ou seja, realizando-se o projeto haverá uma criação de valor de $\mathrm{R} \$ 339.890,84$ na data inicial, após recuperar e remunerar o capital investido, $\mathrm{R} \$$ 166.211,66.

Calculou-se também o VPLa do projeto, obtendo-se um valor positivo igual a $\mathrm{R} \$ 29.822,38$ ou $\mathrm{R} \$ 596,44$ ha 1. Esse valor foi superior ao VPLa $\left(\mathrm{R} \$ 152,56 \mathrm{ha}^{-1}\right)$ obtido por Virgens et al. (2015) ao avaliar a viabilidade econômica de projetos de reflorestamentos com clones de eucalipto no estado da Bahia. Contudo, para decidir se o projeto deve ser aceito, é necessário ainda avaliar outros indicadores.

A TIR do projeto $(10,19 \%)$ foi superior à taxa mínima de atratividade $(6,38 \%)$, indicando que há criação de valor pelo projeto. Ao analisar o risco do projeto, a TIR encontra-se relativamente distante da TMA, apontando para um projeto de baixo risco no que se refere ao retorno financeiro do investimento.

Além disso, utilizaram-se também outros indicadores de rentabilidade para avaliação do projeto. Nesse sentido, o IL obtido foi de 3,04, isto é, a cada R \$ 1,00 investido no projeto, espera-se recuperar após o horizonte de tempo do projeto $\mathrm{R} \$ 3$,04 além da taxa mínima de atratividade (6,38\% a.a). Esse indicador se apresentou elevado quando comparado com o IL $(2,04)$ obtido pela FAMATO (2013) ao analisar a viabilidade econômica da produção de eucalipto destinado à serraria no estado do Mato Grosso. O IL\% também foi calculado, obtendo-se uma rentabilidade real esperada de $204 \%$ em um período de 21 anos, além de recuperar $6,38 \%$ (TMA) ao ano.

O projeto em análise também apresentou um ROIA de 5,45\%. Além de recuperar 6,38\% a.a, obtêm-se um retorno adicional sobre essa taxa de 5,45\% ao ano. Esse valor foi inferior ao ROIA (7,33\%) obtido por Bendlin et al. (2014), quando analisou o retorno de investimento para a produção de toras de eucalipto aos 14 anos na região do Planalto Norte de Santa Catarina.

Com o intuito de complementar ainda mais a análise, calculou-se o ROI, que apresentou um valor de $12,17 \%$ no projeto. Isso significa que a cada $\mathrm{R} \$ 100,00$ investidos recupera-se 6,38\% a.a e mais um adicional de 5,45\% (ROIA) ao ano, que consiste em um retorno de $\mathrm{R} \$ 12,17$ a cada $\mathrm{R} \$ 100,00$.

No projeto, além dos indicadores de rentabilidade, utilizaram-se, também, indicadores de risco. O payback 
simples do projeto foi de 14 anos, indicando que o projeto possui um risco relativamente alto, visto que o período de recuperação do capital se aproxima do final do horizonte de tempo do projeto (21 anos). Contudo, é natural que o projeto florestal em análise apresente payback elevado, uma vez que a maior parte das receitas ocorre nos períodos finais do projeto, embora existam receitas intermediárias. Nesse caso, deve-se utilizar a TIR como o indicador de risco do projeto. Não foi possível obter o payback descontado para o projeto em análise por possuir um fluxo de caixa não convencional.

Diante desses resultados, os indicadores econômicos indicam que o projeto possui uma boa rentabilidade, quando comparado com outros projetos florestais do setor. Isso se deve à produtividade do povoamento florestal e ao valor agregado da madeira destinada à serraria. De acordo com Paiva et al. (2013), as condições de clima e de solo da região a ser reflorestada e o objetivo da produção, ou o uso futuro da floresta, são fatores determinantes para a tomada de decisão de um projeto de investimento florestal.

Após a análise em condições deterministas, isto é, sem incorporar ao projeto uma análise de risco, realizouse uma análise de sensibilidade com a finalidade de analisar o risco do projeto. Para tanto, quantificou-se o impacto sobre o VPL provocado pela variabilidade de cinco estimativas do projeto, uma por vez, mantendo-se inalteradas as demais estimativas (Figura 2).

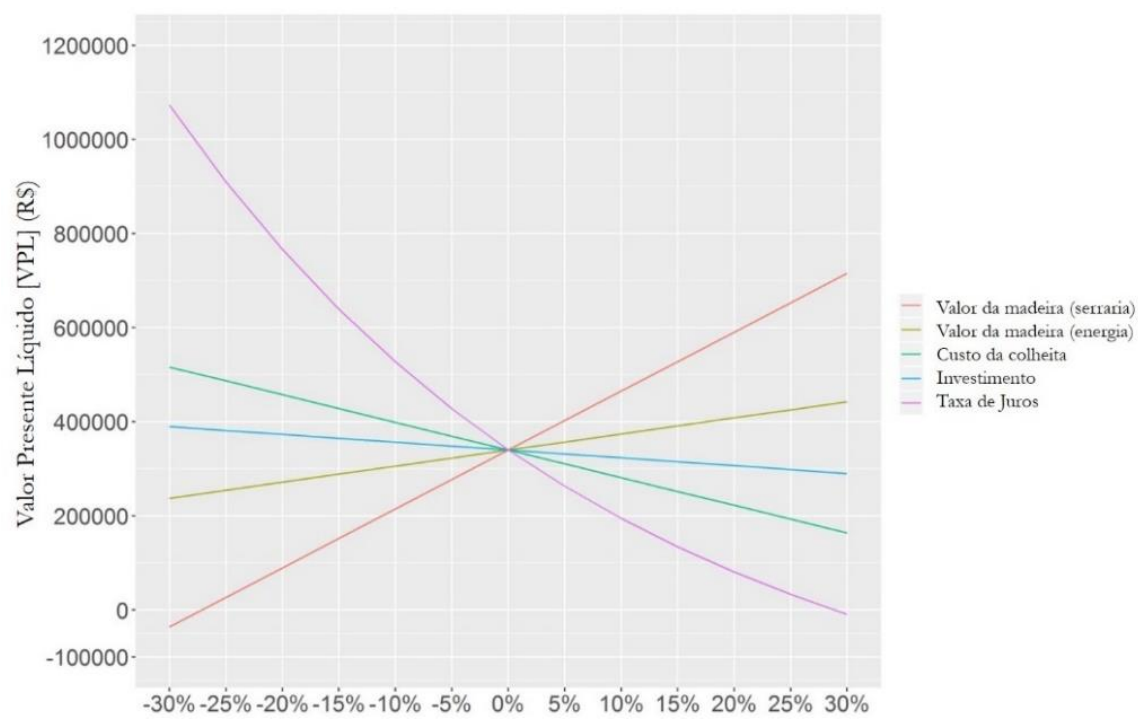

Figura 2. Análise de sensibilidade do VPL em função da variação de cinco estimativas do projeto sem financiamento

O projeto apresentou-se inviável apenas quando aumentou a taxa de juros e diminuiu o preço da madeira (serraria) em $30 \%$. A partir da análise, ordenaram-se as estimativas em ordem decrescente de impacto sobre o VPL: taxa de juros; preço da madeira destinada à serraria; custo da colheita; preço da madeira destinada à energia; e investimento inicial. Segundo Rezende e Oliveira (2013), o VPL é muito sensível a mudanças na taxa de desconto, especialmente no caso de projetos de longo prazo. Na Figura 2, observa-se que há uma correlação positiva entre o VPL e as estimativas relativas aos preços da madeira e uma correlação negativa entre o VPL e as demais estimativas.
A taxa de juros, o preço da madeira destinada à serraria e o custo da colheita são as estimativas críticas do projeto, pois suas retas têm a maior inclinação. Portanto, essas três estimativas devem receber mais atenção durante o desenvolvimento do projeto até sua aceitação e monitoradas durante o prazo do projeto, visto que são as estimativas com menor variação para zerar o VPL. O preço da madeira (serraria) que anula o VPL esperado, denominado ponto de reversão da decisão, foi de $\mathrm{R} \$ 145,74 \mathrm{~m}^{-3}$, correspondente a uma redução de $27,1 \%$ sobre o valor esperado da estimativa $\left(\mathrm{R} \$ 200,00 \mathrm{~m}^{-3}\right)$. Os pontos de reversão da decisão de investimento, relativos às estimativas críticas do projeto, estão apresentados na Tabela 5.

Tabela 5. Pontos de reversão das estimativas críticas do projeto sem financiamento

\begin{tabular}{lrr}
\hline \multicolumn{3}{c}{ Pontos de reversão da decisão (VPL $=0)$} \\
\hline Estimativas críticas & Valor & Variação* \\
Taxa de juros & $10,19 \%$ & $28,83 \%$ \\
Preço da madeira (serraria) & $145,74 \mathrm{R}^{-3} \mathrm{~m}^{-3}$ & $-27,13 \%$ \\
Custo da colheita & $72,61 \mathrm{R} \$ \mathrm{~m}^{-3}$ & $57,85 \%$ \\
\hline
\end{tabular}

*variação relativa à estimativa esperada que anule o VPL do projeto 
Para analisar o impacto do financiamento sobre a viabilidade econômica da produção de eucalipto na região, avaliou-se o fluxo de caixa utilizando a linha de crédito ABC Florestas, com financiamento de $50 \%$ dos custos de implantação na data inicial do projeto (Figura 3). Os indicadores econômicos do projeto considerando o financiamento estão descritos na Tabela 6.

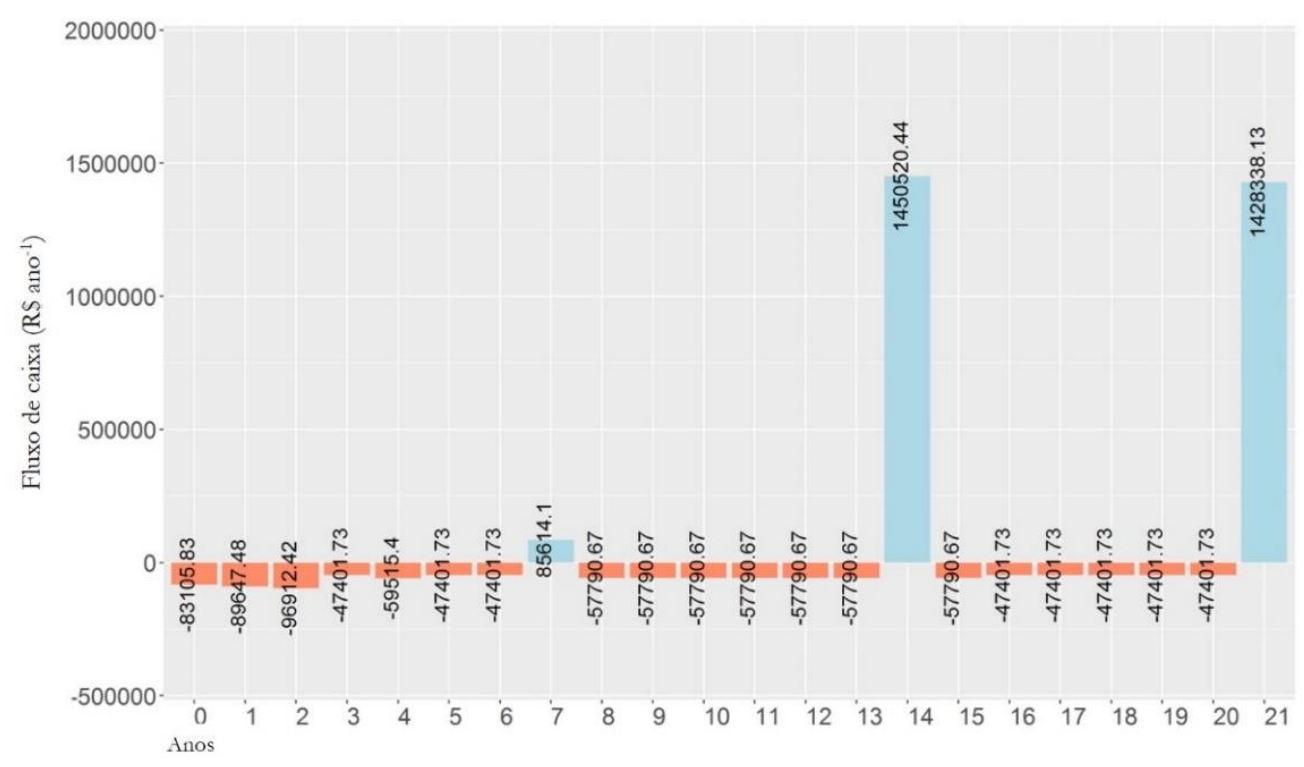

Figura 3. Fluxo de caixa do projeto com financiamento em um horizonte de planejamento de 21 anos

Tabela 6. Indicadores econômicos do projeto de investimento florestal com financiamento em Marco-CE

\begin{tabular}{lrr}
\hline Indicadores econômicos & Unidade & Valores esperados \\
\hline Valor Presente Líquido [VPL] (6,38\%) & $\mathrm{R} \$$ & $365.979,88$ \\
Valor Presente Líquido Anualizado [VPLa] & $\mathrm{R} \$$ & $32.111,46$ \\
Taxa Interna de Retorno [TIR] & $\%$ & 11,02 \\
Índice de Lucratividade [IL] & $\%$ & 5,40 \\
Índice de Lucratividade em Percentual [L\%] & $\% \%$ & 440 \\
Retorno Adicional sobre o Investimento [ROIA] & $\%$ & 8,37 \\
Retorno sobre o Investimento [ROI] & & 15,28 \\
Payback descontado & & Não se aplica \\
Payback simples & 14 \\
\hline
\end{tabular}

De acordo com a Tabela 6, notou-se que o efeito do financiamento sobre o projeto foi um acréscimo de 7,7\% do VPL, o que correspondeu a um aumento de $\mathrm{R} \$$ 26.089,04. O projeto também apresentou um VPLa de $\mathrm{R} \$ 32.111,46$, valor inferior ao VPLa ( $\mathrm{R} \$ 82.851,00)$ encontrado pela FAMATO (2013), quando avaliou a viabilidade econômica da produção de eucalipto para madeira serrada no estado do Mato Grosso, utilizando recursos a uma taxa de juros nominal de 5\%, disponibilizados pelo Banco Nacional de Desenvolvimento Econômico e Social [BNDES].

Com relação aos demais indicadores, houve um aumento significativo de seus valores quando comparado com o cenário sem o financiamento. Isso se deve ao fato de a taxa de juros do financiamento ser menor que a TMA do projeto e ao menor valor desembolsado na data zero, devido ao financiamento de $50 \%$ dos custos de implantação.

A TIR $(11,02 \%)$ foi superior à TMA do projeto e à encontrada no cenário sem financiamento, indicando que o projeto deve ser aceito. Quanto ao payback simples, o tempo de recuperação do capital também foi de 14 anos. E novamente o payback descontado não se aplicou ao projeto em análise.

$\mathrm{Na}$ análise de sensibilidade, o projeto com financiamento apresentou-se inviável somente quando se diminuiu o preço da madeira (serraria) em 30\% (Figura 4). Porém, a variação (diminuição do preço da madeira para serraria) resultou em um VPL de $-\mathrm{R} \$$ 9.835,53, enquanto que, no cenário sem o financiamento, obtevese um VPL de -R \$35.924,56 ao diminuir o preço da madeira (serraria) em 30\%. 


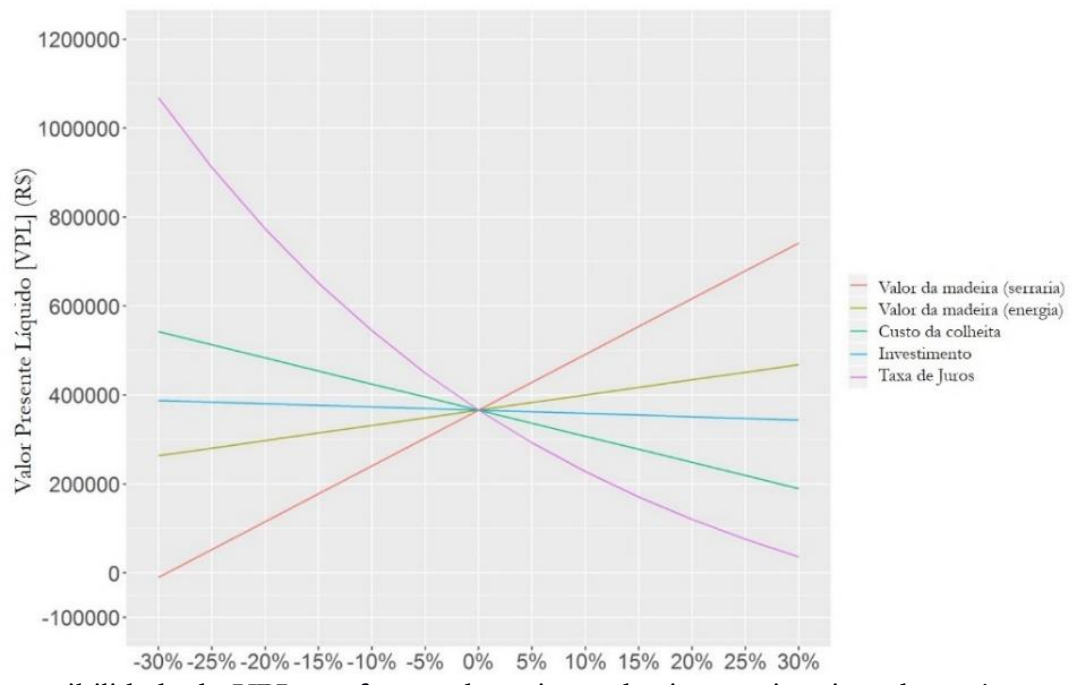

Figura 4. Análise de sensibilidade do VPL em função da variação de cinco estimativas do projeto com financiamento

A ordem decrescente de impacto provocado pelas estimativas sobre o VPL foi a mesma identificada no cenário sem o financiamento. Quanto ao preço da madeira (serraria), por exemplo, sua variação em -10\% provocou uma redução de 34\% no VPL esperado do projeto. Virgens et al. (2015), ao reduzir o preço da madeira pelo mesmo percentual, verificaram uma redução de $60 \%$ no VPL, quando realizaram a análise de sensibilidade em projetos de reflorestamento com clones de eucalipto no estado da Bahia. Isso evidencia como o
VPL é sensível a mudanças no preço da madeira em projetos florestais.

As estimativas críticas do projeto também corresponderam à taxa de juros, ao preço da madeira (serraria) e ao custo da colheita no cenário com financiamento. $\mathrm{Na}$ Tabela 7, estão descritos os pontos de reversão da decisão de investimento dessas estimativas, que foram diferentes dos obtidos no cenário sem financiamento.

Tabela 7. Pontos de reversão das estimativas críticas do projeto com financiamento

\begin{tabular}{lrr}
\hline & Pontos de reversão da decisão (VPL=0) & \\
\hline Estimativas críticas & Valor & *Variação \\
Taxa de juros & $11,02 \%$ & $35 \%$ \\
Preço da madeira (serraria) & $\mathrm{R} \$ 141,57 \mathrm{~m}^{-3}$ & $-29,21 \%$ \\
Custo da colheita & $\mathrm{R} \$ 74,65 \mathrm{~m}^{-3}$ & $62,29 \%$ \\
\hline
\end{tabular}

*variação relativa à estimativa esperada que anule o VPL do projeto

Diante da análise de sensibilidade realizada para os dois cenários, sem financiamento e com financiamento, constatou-se que na maior parte das variações das estimativas esperadas se obteve um VPL positivo.

\section{Conclusões}

A produção de eucalipto no polo moveleiro de Marco-CE apresenta-se viável economicamente, pincipalmente se houver financiamento no momento da implantação do povoamento florestal.

A análise de sensibilidade demonstra que o projeto possui um baixo risco, apesar do longo prazo.

\section{Agradecimentos}

Agradeço à Agência de Desenvolvimento do estado do Ceará [ADECE], ao Banco do Nordeste do Brasil $[\mathrm{BNB}]$ e à Empresa Brasileira de Pesquisa Agropecuária
[EMBRAPA] pela contribuição no desenvolvimento do trabalho.

\section{Referências}

Associação dos Moveleiros de Marco [AMMA]. 2008. Plano de desenvolvimento do Arranjo Produtivo Local do Marco - Ceará. Disponível em: $<$ http://docplayer.com.br/125814-Plano-dedesenvolvimento-do-arranjo-produtivo-local-demoveis-do-marco-ceara.html>. Acesso em: 18 jun. 2016.

Bacha, C.J.C. 2014. Tributação no Agronegócio: Análise de seus Impactos sobre Preços, Folha de Pagamento e Lucros. Editora Alínea, Campinas, São Paulo, Brasil.

Banco Central do Brasil [BCB]. 2016. Focus - Relatório de Mercado. Disponível em: $<$ https://www.bcb.gov.br/pec/GCI/PORT/readout /R20160902.pdf>. Acesso em: 07 set. 2016. 
Bendlin, L.; Senff, C.O.; Pedro, J.J.; Stafin, O.O. 2014. Custos de produção, expectativas de retorno e risco associado ao plantio de eucalipto na região do Planalto Norte - Catarinense/Brasil. In: XXI Congresso Brasileiro de Custos, 2014, Natal, Rio Grande do Norte, Brasil. Disponível em: $<$ https://anaiscbc.emnuvens.com.br/anais/article/vi ew/3677>. Acesso em: 01 out. 2016.

BRASIL. 1973. Lei n. 5.889, de 8 de junho de 1973. Estatui normas reguladoras do trabalho rural. Diário Oficial da União, Brasília, 11 jun. 1973. Disponível em: <http://www.planalto.gov.br/ccivil_03/leis/L5889.h tm>. Acesso em: 27 set. 2016.

BRASIL. 2014. Lei n. 12.973, de 13 de maio de 2014. Altera a legislação tributária federal relativa ao Imposto sobre a Renda das Pessoas Jurídicas - IRPJ, à Contribuição Social sobre o Lucro Líquido - CSLL, à Contribuição para o PIS/PASEP e à Contribuição para o Financiamento da Seguridade Social COFINS. Diário Oficial da União, Brasília, 14 maio 2014. Disponível em:

<http://www.planalto.gov.br/ccivil_03/_ato20112014/2014/Lei/L12973.htm>. Acesso em: 15 set. 2016.

Departamento Nacional de Obras Contra as Secas [DNOCS]. 2002. Perímetro irrigado Baixo-Acaraú. Disponível em:

<http://www.dnocs.gov.br/ dnocs/doc/canais/peri metros_irrigados/ce/baixo_acarau.html>. Acesso em: 25 ago. 2016.

Federação da Agricultura e Pecuária do Estado de Mato Grosso [FAMATO]. 2013. Diagnóstico de Florestas Plantadas do Estado de Mato Grosso. Imea, Cuiabá, Mato Grosso, Brasil. Disponível em:

<http://www.imea.com.br/upload/pdf/arquivos/R EV_Relatorio_final_floresta_plantada_-

1_com_capa.pdf >. Acesso em: 01 out. 2016.

Foelkel, C. 2010. Eucalipto: uso da poda ou desrama nas árvores. Revista da Madeira 124. Disponível em: <http://www.remade.com.br/br/revistadamadeira_ materia.php? num $=1484 \&$ subject $=$ Eucalipto\&title $=\bar{E}$ ucalipto $\% 20$ uso $\% 20 \mathrm{da}^{2} \% 20$ poda $\% 20$ ou $\% 20$ desrama $\% 20$ nas $\% 20 \%$ E1rvores $>$. Acesso em: 07 set. 2016.

Indústria Brasileira de Árvores [IBÁ]. 2016. Relatório Ibá 2016. Disponível em:

<http://iba.org/images/shared/Biblioteca/IBA_Rela torioAnual2016_.pdf $>$. Acesso em: 22 set. 2016.

Lapponi, J.C. 2007. Projetos de Investimento na Empresa. Editora Elsevier, Rio de Janeiro, Rio de Janeiro, Brasil.

Lima Júnior, V.B.; Rezende, J.L.P.; Silva, M.L. da. 1999. Os estágios de produção e a idade ótima de corte: diferença entre a teoria da produção instantânea e a preferência temporal na produção florestal. Revista Árvore 23(4): 393-401.
Ministério da Agricultura, Pecuária e Abastecimento [MAPA]. 2016. Sistema de Agrotóxicos Fitossanitários - AGROFIT. Disponível em: <http://agrofit.agricultura.gov.br/agrofit_cons/princ ipal_agrofit_cons $>$. Acesso em: 12 set. 2016 .

Mora, A.L.; Garcia, C.H. 2000. A Cultura do Eucalipto no Brasil. Sociedade Brasileira de Silvicultura, São Paulo, São Paulo, Brasil. Disponível em: <http://www.ipef.br/publicacoes/a_cultura_do_euc alipto_no_Brasil/>. Acesso em: 18 jun. 2016.

Pacheco, E.P. 2000. Seleção e Custo Operacional de Máquinas Agrícolas. EMBRAPA, Rio Branco, AC, Brasil. Disponível em: <https://www.EMBRAPA.br/busca-depublicacoes/-/publicacao/495355/selecao-e-custooperacional-de-maquinas-agricolas $>$. Acesso em: 27 ago. 2016.

Paiva, H.N. de; Jacovine, L.A.G; Trindade, C.; Ribeiro, G.T. 2013. Cultivo de Eucalipto: Implantação e Manejo. Editora Aprenda Fácil, Viçosa, MG, Brasil.

Rezende, J.L.P. de; Oliveira, A.D. de. 2013. Análise Econômica e Social de Projetos Florestais. 3ed. Editora UFV, Viçosa, Minas Gerais, Brasil.

Sá, C.A. 2014. Fluxo de Caixa: a Visão da Tesouraria e da Controladoria. 5ed. Editora Atlas, São Paulo, SP, Brasil.

Serviço Florestal Brasileiro [SFB]. 2016. Guia de Financiamento Florestal. MMA, Brasília, DF, Brasil. Disponível em: <http://www.florestal.gov.br/destaques/guia-definanciamento-florestal-2016>. Acesso em: 07 set. 2016.

Souza, A.; Clemente, A. 2008. Decisões Financeiras e Análise de Investimentos: Fundamentos, Técnicas e Aplicações. Editora Atlas, São Paulo, São Paulo, Brasil.

Virgens, A.P. das; Freitas, L.C. de; Luz, D.S.; Moreira, A.C.D. 2015. Análise econômica e de sensibilidade em projetos de reflorestamentos no Estado da Bahia. Enciclopédia Biosfera 11(21): 120-127. Disponível em:

<http://www.conhecer.org.br/enciclop/2015b/agrar ias/analise $\% 20$ economica $\% 20 \mathrm{e} \% 20 \mathrm{de} \% 20$ sensibilida de.pdf>. Acesso em: 10 set. 2016.

Wilcken, C.F.; Lima, A.C.V.; Dias, T.K.R.; Masson, M.V.; Ferreira Filho, P.J.; Dal Pogetto, M.H.F. do A. 2008. Guia Prático de Manejo de Plantações de Eucalipto. FEPAF, Botucatu, São Paulo, Brasil. Disponível em:

<http://www.iandebo.com.br/pdf/plantioeucalipto.p df $>$. Acesso em: 25 ago. 2016. 